\title{
Expression of adult polycystic renal disease in a 17-year-old male
}

\author{
*A. O. Adeyinka and P. O. Ibinaiye \\ Department of Radiology, University College Hospital, Ibadan, Nigeria
}

\section{Summary}

Autosomal Dominant Polycystic Kidney Disease (ADPKD) is found mostly in the middle-aged group. We report a rare occurrence of ADPKD in a 17-year-old male student with clinical presentation of bilateral loin pains and total haematuria. Clinical diagnosis of Acute-on-Chronic Glomerulonephritis was made. However Ultrasound and Intravenous Urography confirmed the diagnosis of Adult Polycystic Disease. The possible embryogenesis and associated anomalies of ADPKD and the radiological findings were reviewed.

Key -words: Autosomal dominant, Ultrasonography, Polycystic kidney, Urography, Gilomerulonephritis.

\section{Résumé}

La maladie polykystique des reins dominée par autosome (MPRDA) est trouvée principalement chez la tranche d'âge moyen. Nous rapportons la fréquence de MPRDA chez un étudiant du sexe masculin âgé de 17 ans d'une présentation clinique de la douleurs bilatérale dans les reins et hématurie totale diagnostique clinique de la glomerulonephrites aigueen-chronique a été effectuée. Toutefois, l'échographie et l'urographie intraveineuse ont confirmé le diagnostique de la maladie Polykystique chez un adulte. L'embrogenèse possible et une anormalie liée avec MPRDA et des résultats radiojogiques ont été passés en revue Deciphalique-Dipus.

\section{Introduction}

Autosomal Dominant Polycystic Kidney Disease (ADPKD) is one of the most common inherited disorders in humans. It is the most frequent genetic cause of renal failure in adults, accounting for $10 \%$ of patients on dialysis in the United States '. ADPKD is a multi-systemic and progressive disorder characterized by formation and enlargement of cysts in the kidney and other organs (e.g. liver, pancreas, spleen). However, this disease rarely manifests itself before middle age ${ }^{2,3}$. Progressive renal failure occurs in middle-aged to older adults as the cysts become larger and the functioning renal parenchyma becomes smaller in volume ${ }^{3}$. This is the "type III" cystic disease in the Potter classification, but it is rarely manifested prenatal or in children."

The rarity of ADPKD manifesting in the teenager, prompted the author to report this case.

\section{Case history}

A.B. was a seventeen-year-old undergraduate male student of the University of Ibadan. He presented at medical emergency unit of University College Hospital, Ibadan via the University Health Centre with a 5-day history of bilateral loin pains, total haematuria, severe headache and nausea. The systemic review was not contributory. Family and social history showed that he was the first child of the family of four

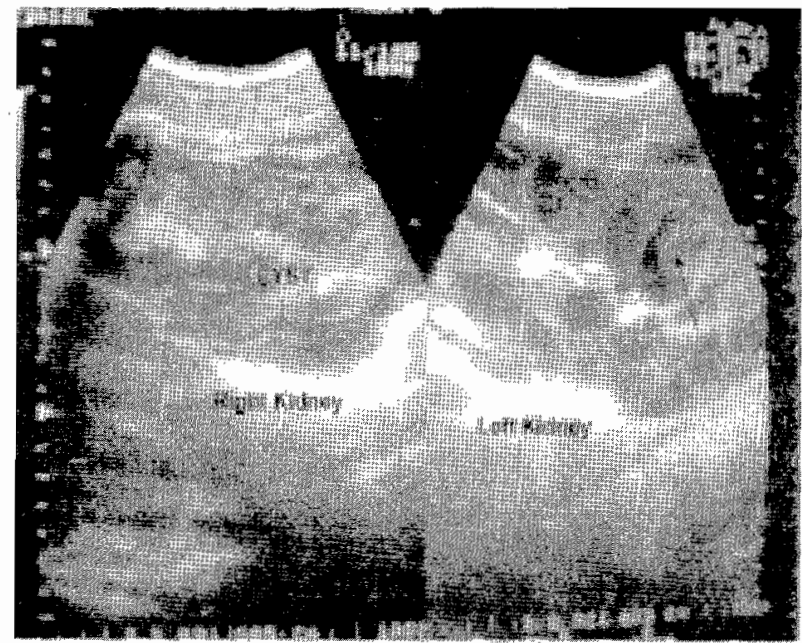

Fig. 1 Abdominal ultrasound showing multiple non-communicating cysts of varying sizes with low level echoes seen in one of the cysts (arrow)

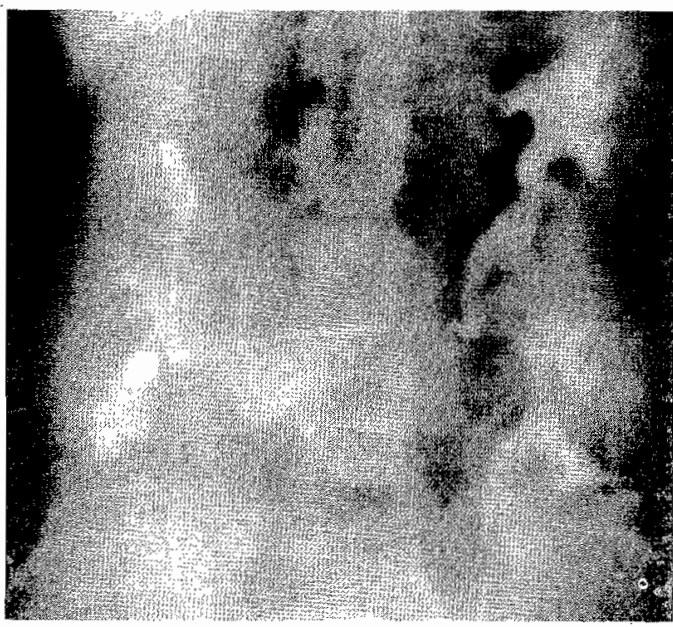

Fig. 2 Intravenous urogram - showing elongated, spreading and crescentic deformities of the calyceal systems bilaterally

children. The father died of kidney related disease. His other siblings were well and healthy. He did not drink alcohol or smoke cigarette.

On examination, he was acutely ill-looking, not pale, afebrile, anicteric, no facial or pedal edema. He was conscious and well oriented in person, place and time. The Pulse Rate was $100 \mathrm{~b} / \mathrm{min}$ and Blood Pressure was $180 / 130 \mathrm{mmHg}$. Heart sounds were normal.

The abdominal examination revealed bilateral flank tenderness and ballotable kidneys on palpation. The Liver, Spleen and other systems were essentially normal. A clinical diagnosis of acute-on-chronic glomerulonephritis was made. Urinalysis showed red blood cells +++, protein ++, but glucose was negative. Urine culture was negative. Serum chemistry profile including calcium and phosphorus were within normal limits. Complete blood count was also normal.

\footnotetext{
*Correspondence
} 
Abdominal ultrasound [fig. 1] showed enlarged right and left kidneys measuring $18.5 \mathrm{~cm} \times 12.6 \mathrm{~cm}$ and $117.0 \mathrm{~cm} \times 12.0 \mathrm{~cm}$ respectively. Both kidneys showed multiple noncommunicating huge cysts of varying sizes, the largest measured $7.5 \mathrm{~cm} \times 4.5 \mathrm{~cm}$. There were low-level echoes seen within some of the cysts suggesting hemorrhage into the cysts. The liver, pancreas, spleen and gall bladder were within normal limits and devoid of cysts.

Intravenous Urogram [fig.2] showed bilateral large kidneys but there was prompt and satisfactory excretion of contrast medium bilaterally. There was also an elongation, spreading and crescenteric deformity of the pelvi-calyceal systems. Abdominal computerized tomography scan requested could not be done as patient opted to go abroad for further treatment and was subsequently lost to follow-up.

\section{Discussion}

Majority of individuals with Autosomal Dominant Polycystic Kidney Disease (ADPKD) live for decades without developing symptoms. For this reason, ADPKD is often called "Adult Polycystic Kidney Disease". Yet in some cases cysts may form earlier, even in the first years of life. The cysts were discovered in this case report presented at the age of 17 years. The disease is thought to occur equally in men and women and there is no racial discrimination ${ }^{1,3}$. However, some studies suggest that it occurs more often in whites than in blacks and more often in females than in males ${ }^{1,2,3}$. High blood pressure occurs early in the disease, often before cysts appear. This case report presented had elevated BP of $180 / 130 \mathrm{~mm} / \mathrm{Hg}$.

ADPKD is one of the most common inherited disorders. The phrase "autosomal dominant" means that if one parent has the disease, there is a 50-percent chance that the disease will pass on to a child. In this case report, the father was reported to have died of a kidney related disease, so it could be presumed that he could have inherited the disease from his father, although new mutations may account for onefourth of new cases. In some rare cases, ADPKD occurs spontaneously in the child soon after conception, in these cases the disease is not inherited from the parents ${ }^{2}$. Shokier ${ }^{2}$ documented that the manifestations of adult polycystic disease of the kidneys are reported in fetal life and during infancy.

Heteboer $e t a l^{5}$ and Qian et $a l^{6}$ documented that ADPKD is a genetically heterogeneous condition with at least involvement of three genes.

Ultrasound is the most useful imaging technique for diagnosing ADPKD, and it can detect cysts from $1-1.5 \mathrm{~cm}$. Ultrasound also is useful for exploring abdominal extra renal features of ADPKD (eg liver, pancreas and spleen cysts).

The diagnostic criteria for PKD $^{1}$ were established by Ravine et al ${ }^{7}$ is as follows:

At least 2 cysts in 1 kidney or 1 cyst in each kidney in patient at risk, younger than 30years

- At least 2 cysts in each kidney in patient at risk, aged 3059 years.

At least 4 cysts in each kidney for patients at risk, aged 60 years and older

- Presence of hepatic or pancreatic cyst helps support

\section{diagnosis.}

Intravenous Urography (IVU) only diagnoses ADPKD in advanced stages because of the distortion of calyces. More expensive imaging methods such as Computed Tomography (CT scan) and Magnetic Resonance Imaging (MRI) also can detect cysts, but these methods usually are not required because ultrasound provides adequate information ${ }^{7,8}$. Doppler studies and 2-dimensional echocardiography are used to rule out a mitral prolapse, which often is associated with $\mathrm{ADPKD}^{8}$. ADPKD is also associated with berry aneurysm of the cerebral arteries ${ }^{9}$, which may require cerebral angiography

The treatment of ADPKD could be medical or surgical. The medical treatment must be tailored toward the control of symptoms associated with ADPKD. Analgesics could control pain and headache, antibiotics could be used to treat urinary tract infection that is common in ADPKD and antihypertensive to achieve blood pressure less than $130 /$ $85 \mathrm{mmHg}$. In end stage renal disease, dialysis and kidneys transplantation can be carried out. Klatt ${ }^{3}$ documented that healthy (non-PKD)kidneys transplanted into PKD patients do not develop cysts.

In conclusion, the manifestation of Adult Polycystic Disease in younger age groups (teenagers) with high blood pressure, Loin pains and haematuria, should always be contemplated. Abdominal Ultrasonography and Intravenous Urography can achieve early detection of the disease and thus provide the required template for effective management of the patient.

\section{References}

1. Roser Tora. Polycystic Kidney Disease. Emed. J., 2002; 3.

2. Shokeir M H.Expression of "adult" Polycystic renal disease in the fetus and new born.Clin Genet., 1978; 14: 61-72.

3. Klatt E C 2002). Pathology of Renal Cystic disease. Availabe at

http://medlib.med.utah.edu/webpath/webpath.html\#MENU.

4. Harris PC, Thomas S and Ratcliffe P J. Rapid Genetic Analysis of Families with Polycystic Kidney disease 1 by means of a microsatellite marker. Lancet, 1991, 338: 1484- 1487.

5. Hateboer N, vDijk M A and Bogdanova N. Comparison of phenotypes of polycystic Kidney disease types 1 and 2. European PKD1 - PKD2 study group. Lancet 1999; 353: $103-107$.

6. Qian F, Watnick T J and Onuchic L F. The Molecular basis of focal cyst formation in human autosomal dominant polycystic kidney disease type 1. Cell, 1996; 87: 979-987.

7. Ravine D, Gibson R N and Walker R G. Evaluation of ultraonographic diagnostic Criteria for autosomal dominant polycystic Kidney disease. Lancet, 1994; 343: 824-827.

8. Parfrey P S, Bear J C and Morgan J. The diagnosis and Prognosis of autosomal dominant polycystic Kidney disease.N. Engl J. Med., 1990; 323: 1085 - 1090.

9. Chauveau D, Pirson $Y$ and Verellen-Dumoulin C. Intracranial aneurysms in Autosomal Dominant Polycystic Kidney disease. Kidney Int, 1994; 45: 1140 - 1146. 